IFN Working Paper No. 748, 2008

\title{
Efficiency and the Provision of Open Platforms
}

Joacim Tåg 


\title{
Efficiency and the Provision of Open Platforms
}

\author{
Joacim Tåg *†
}

April 10, 2008

\begin{abstract}
Private firms may not have efficient incentives to allow third-party producers to access their platform or develop extensions for their products. Based on a two-sided market model, I discuss two reasons for why. First, a private firm may not be able to internalize all benefits from cross-group externalities arising with third-party extensions. Second, firms may have strategic incentives to shut out third-parties because it relaxes competition.
\end{abstract}

Keywords: Platforms; Two-sided markets; open versus closed.

JEL Codes: D40, L10.

\footnotetext{
${ }^{*}$ Swedish School of Economics and Business Administration, FDPE and HECER (Arkadiankatu 7, 00101 Helsinki, Finland) and the Research Institute of Industrial Economics (IFN) (P.O. Box 55665, SE-102 15 Stockholm, Sweden). E-mail: joacim.tag@hanken.fi.

${ }^{\dagger}$ Financial support in the form of a GS Fellowship position awarded by the Finnish Doctoral Programme in Economics is gratefully acknowledged. I thank Rune Stenbacka for insightful comments on early drafts.
} 


\section{Introduction}

Do private firms allow third-parties to access their platform or develop extensions for their product when it is socially desirable? This question has repeatedly been a concern for anti-trust authorities. For example, in 1955 the FCC in the United States agreed with the AT\&T Bell System that an attachment to phones (the Hush-A-Phone) that helped to reduce noise could not be marketed and sold independently since it was a "foreign attachment" to the AT\&T network. The FCC also concluded that all telephone equipment should be sold by the network operator. This decision was however overturned on appeal by the D.C. Circuit. ${ }^{1}$ In line with this appeal, the FCC later (in 1968) ruled that another attachment marketed by an independent firm, the Carterfone, should be able to be used on the AT\&T Bell System network.

Another example is the anti-trust case Eastern Kodak Co. v. Image Technical Services, Inc ${ }^{2}$. Kodak had excluded third-parties from being able to service the equipment they had sold. The Supreme Court, however, ruled that external firms should be able to service Kodak's equipment.

In contrast to previous literature on this question, I take a two-sided market approach and propose two new reasons for why private incentives may be insufficient. First, a private firm may not be able to internalize all benefits from cross-group externalities arising when third-parties are involved. Second, firms may have strategic incentives to shut out producers of third-party extensions because closed platforms relaxe competition for consumers.

My arguments are based on the recent literature on two-sided markets. $^{3}$ In two-sided markets, platforms intermediate transactions between two groups of agents. The groups impose externalities on each other, and platforms should set price to each group so as to best internalize these externalities. If we assume the groups are consumers and third-party producers of extensions to the platform, we can analyze if platforms' incentives to deal with both groups instead of just one are socially efficient.

\footnotetext{
${ }^{1}$ Hush-A-Phone Corp., 20 .F.C.C. 391, 420 (1955) (Decision), rev'd, 238 F2.d 266 (D.C. Cir. 1956)

${ }^{2}$ Eastern Kodak Co. v. Image Tech Services, 125 F3d. 1995 Ninth Circuit, 1997

${ }^{3}$ Seminal papers include Rochet and Tirole (2003), Caillaud and Jullien (2003), Rochet and Tirole (2006), Hagiu (2006) and Armstrong (2006).
} 
I start out in section 2 by setting up and discussing a simple monopoly model. I show that social incentives to allow third parties access to the platform are likely stronger than private incentives. I then introduce competition between platforms in section 3 to show that platforms may inefficiently choose to commit to excluding third-parties because it relaxes competition for consumers.

The literature on vertical relations in complementary markets is closely related to this paper. ${ }^{4}$ The central "Chicago School" argument - see for example Bowman (1957) and Bork (1978) — says that private and social incentives for vertical integration in complementary markets should coincide. The reason is that a platform should have no incentives to vertically integrate into the supply of a complementary good unless it is efficient, since it can always raise the price of the platform to internalize any potential surplus from the sale of the complementary good.

But the basic "Chicago School" argument can break down for several reasons. For example, as Choi and Stefanadis (2001) show, integration may protect against entry by competitors, and as Whinston (1990) shows, that if the if the downstream product has other uses, integration might be used to leverage monopoly power into the other market.

Since I depart from the two-sided market literature, I use several assumptions commonly not used in this literature. First, I place heavy emphasis on the existence of cross-group externalities between consumers and thirdparty extension providers. All else equal, increased participation by one group lead to more participation by the other. Second, firms in my model set a fee that third-partiy producers must pay for the right to develop an extension. This fee can also be negative, in which case it is a subsidy intended to encourage participation by third-parties. Third, I consider several atomistic third-party extension providers that do not compete with each other and take the fee set by the firm as given. Further, the pricing decision of third-party extension providers is completely "blackboxed" and they are simply assumed to profit from interacting with consumers. The drawback

\footnotetext{
${ }^{4}$ The literature is vast and includes for example analyses of tying complementary products (E.g. Whinston (1990), Carlton and Waldman (2002), Choi and Stefanadis (2001) and Nalebuff (2004)), innovation and integration in systems markets (e.g. Farrell and Katz (2000)), systems versus component competition (e.g. Matutes and Regibeau (1988), Economides (1989), Farrell et al. (1998), non-price discrimination (e.g. Economides (1998)), and intersystem competition and vertical foreclosure (e.g. Church and Gandal (2000)).
} 
Open

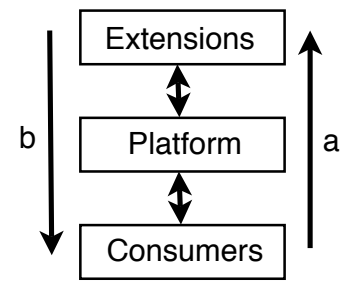

Closed

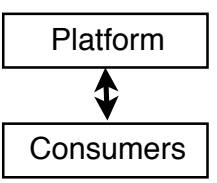

Figure 1: An open platform allows for third-party extensions. A closed one does not.

of this approach is that I assume away potentially important strategic interactions between the price of the main product and the price of extensions set by third-party providers. The benefit is a new perspective emphasizing cross-group externalities and pricing to internalize them.

\section{All Benefits May not be Internalized}

\section{$2.1 \quad$ Setup}

A monopoly firm has developed a platform of quality $v>0$. The platform can either be open or closed. An open platform grants third-party producers access to the platform so they can develop extensions for it. A closed one does not (figure 1 illustrates).

If open, the firm sets a fee (or subsidy) for the right to develop an extension. This fee is set simultaneously with the price for the platform. Consumers and extension providers then observe prices and fees, form rational expectations regarding the participation of the opposite group, and finally simultaneously make their participation decisions. Marginal costs are zero, but costs for providing and open platform instead of a closed are $F$.

Consumers are distributed uniformly over the unit interval, $x \in[0,1]$ with the platform located at $x=0$. Consumers face a transportation cost $t$ for each unit of distance travelled on the line. It is sufficiently large so that at optimum some consumers always choose to stay out of the market. ${ }^{5}$. Consumer $i$ 's location, $x_{i}$, then specify her preference for the firm's platform

\footnotetext{
${ }^{5}$ The assumption needed when the platform is closed is $t>\frac{v}{2}$ and when open is $t>\frac{(a+b)(a+b+v)}{4 f}$.
} 
and she receives utility $u_{i}=\left(v-t x_{i}\right)+b n_{e}-p$ if she purchases the platform.

The price of the platform is $p$ and $n_{e}$ denotes the number of thirdparty extensions available for the platform. The parameter $b>0$ measures the additional value of the platform to the consumer for each third-party extension available.

The extension providers are independent monopolists. They are treated as atomistic and are uniformly distributed on the unit interval, $y \in[0,1]$. They are heterogeneous in terms of coming up with a business idea, setting up shop, and providing an extension. These costs are scaled by $f$. Each extension provider is able to extract an expected profit of $a>0$ from each consumer purchasing the platform.

Extension provider $j$ has total profits $\pi_{j}=a n_{c}-f y_{j}-s$. If $s$ is positive, it represents a fee that must be paid for the right to develop an extension. If $s$ is negative it is a subsidy intended to encourage the development of extensions. Development costs are sufficiently large so in equilibrium some developers always choose to remain inactive. ${ }^{6}$ Finally, the total number of consumers purchasing the platform is $n_{c}$.

\subsection{Optimal Price and Fee/Subsidy}

When the platform is closed demand for the platform and the location of the consumer indifferent between buying the platform and not buying the platform is $n_{c}(p)=x_{i n}=\frac{1}{t}(v-p)$. The firm sets price to maximize

$$
\pi_{C}=p n_{c}
$$

Optimal price is $p_{C}^{*}=\frac{1}{2} v$ and profits are $\pi_{C}^{*}=\frac{1}{4 t} v^{2}$. Consumer surplus is $C S_{C}=\int_{0}^{x_{i n}^{*}}\left(v-t x-p_{C}^{*}\right) d x=\frac{1}{8 t} v^{2}$. The second order condition $-\frac{2}{t}<0$ is satisfied.

When the platform is open, conditional on the number of extensions available, demand for the platform and the location of the consumer indifferent between buying the platform and not buying is $n_{c}^{\text {cond }}\left(p, n_{e}\right)=x_{i n}=$ $\frac{1}{t}\left(v+b n_{e}-p\right)$. Conditional on the number of consumers buying the platform, demand for developing extensions for the platform and the location of the extension provider indifferent between providing an extension and not providing one is $n_{e}^{\text {cond }}\left(s, n_{c}\right)=y_{i n}=\frac{1}{f}\left(a n_{c}-s\right)$. We can obtain con-

\footnotetext{
${ }^{6}$ The assumption needed is $f>\frac{(a+b)^{2}}{4 t-2 v}$.
} 
sumer demand for the platform and demand for developing extensions for the platform as a function of $p$ and $s$ by simultaneously solving the equations $n_{c}=n_{c}^{c o n d}\left(p, n_{e}\right)$ and $n_{e}=n_{e}^{c o n d}\left(s, n_{c}\right)$.

This gives $n_{c}=\frac{1}{f t-a b}(f(v-p)-b s)$ and $n_{e}=\frac{1}{f t-a b}(a(v-p)-s t)$. The firm sets price to consumers and the fee (subsidy) to extension providers to maximize

$$
\pi_{O}=p n_{c}+s n_{e} .
$$

Optimal prices are

$$
p_{O}^{*}=\frac{v(2 f t-a(a+b))}{4 f t-(a+b)^{2}} \text { and } s_{O}^{*}=\frac{v f(a-b)}{4 f t-(a+b)^{2}} .
$$

The profit, consumer surplus, and total extension provider profit at these prices are

$$
\begin{aligned}
\pi_{O}^{*} & =\frac{f v^{2}}{4 f t-(a+b)^{2}}, \\
C S_{O}^{*} & =\int_{0}^{x_{i n}^{*}}\left(v+b n_{e}^{*}-t x-p_{O}^{*}\right) d x=\frac{2 f^{2} t v^{2}}{\left((a+b)^{2}-4 f t\right)^{2}},
\end{aligned}
$$

and

$$
\Pi=\int_{0}^{y_{i n}^{*}}\left(a n_{c}^{*}-f y-s_{O}^{*}\right) d y=\frac{(a+b)^{2} f v^{2}}{2\left((a+b)^{2}-4 f t\right)^{2}} .
$$

The second order conditions are $-\frac{2 f}{f t-a b}<0$ and $\frac{1}{(a b-f t)^{2}}\left(4 f t-(a+b)^{2}\right)>0$. I assume that $4 f t-(a+b)^{2}>0$ to ensure that these hold. This says that the cross-group externalities are sufficiently small in relation to the transportation costs and the costs for developing extensions. At optimum, the price and the fee (subsidy) depends on the size of the cross-group externalities. The firm balances the price and the fee (subsidy) to best internalize externalities. Extension providers are subsidized if $b>a$. Profits are increasing in cross-group externalities and in the intrinsic quality of the platform. Because it becomes harder to attract consumers and extension providers, profits are decreasing in consumer transportation costs and in the costs for developing extensions.

\subsection{Private versus Social Incentives}

We can now compare private and social incentives to allow third parties to access the platform and develop extensions for it. A private firm will provide 
an open platform if $\pi_{O}^{*}-\pi_{C}^{*}-F>0$. In comparison, the socially optimal choice is to provide an open platform if $\pi_{O}^{*}-\pi_{C}^{*}-F+\left(C S_{O}^{*}-C S_{C}^{*}+\Pi^{*}\right)>0$. The difference between these two equations,

$$
C S_{O}^{*}-C S_{C}^{*}+\Pi^{*}=\frac{(a+b)^{2}\left(12 f t-(a+b)^{2}\right) v^{2}}{8 t\left((a+b)^{2}-4 f t\right)^{2}}
$$

is positive for $a, b>0$ and $4 f t-(a+b)^{2}>0$. The reason private incentives differ from social incentives is that some of the benefits from cross-group externalities goes to consumers and some to extension providers.

Proposition 1. Private incentives to provide an open platform may be weaker than social incentives because a private firm may not be able to internalize all benefits from granting third-party producers access to the platform.

Unless the platform can extract all benefits from cross-group externalities, the result in proposition 1 holds. Stepping out of this stylized model, private incentives are too weak as long as $\left(C S_{O}-C S_{C}+\Pi\right)>0$.

\section{No Third-parties May Relax Competition}

\subsection{Setup}

Consider now an extension to the model above. There are two platforms of the same intrinsic value $v>0$. They can be either closed or open and fixed development costs, cost for opening the platform, and marginal costs are zero. Consumers buy only one platform, but third-parties may provide an extension for any platform that is open. ${ }^{7}$

In stage 1 , the firms simultaneously decide if their platform should be open or closed. Figure 2 illustrate possible outcomes.

In stage 2, firms observe the choice the rival made. Firms then simultaneously set price to consumers; firms that provided open platforms also set a fee or subsidy to third-parties for the right to access the platform. Consumers and extension providers then observe prices and fees or subsidies. They form rational expectations regarding the participation of the opposite group. Consumers buy the platform yielding the highest utility and third-

\footnotetext{
${ }^{7}$ Consumers singlehome and third-parties multihome. See e.g. Armstrong (2006) and Choi (2006) for similar setups.
} 


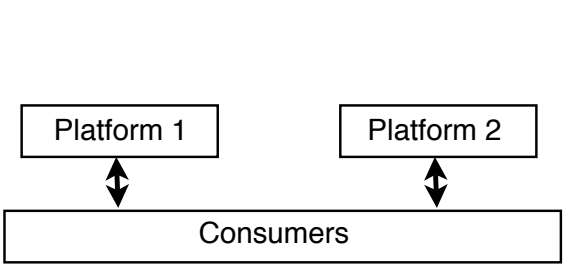

Open-Closed

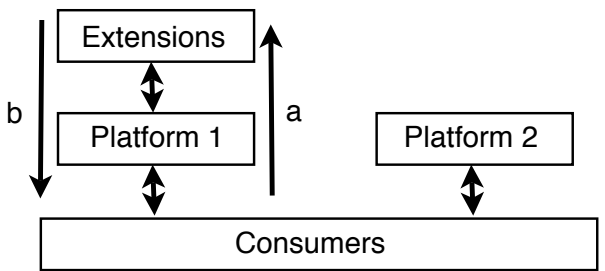

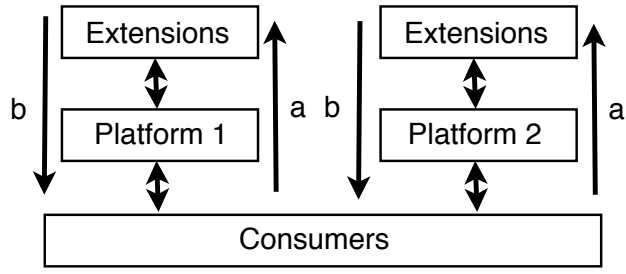

Closed-Open

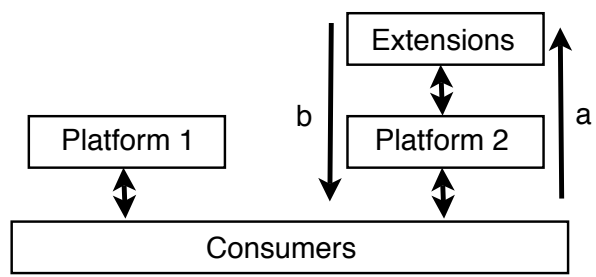

Figure 2: In stage 1, firms choose between providing an open or a closed platform. These are the possible outcomes of that choice.

parties decide for each open platform separately if they should provide an extension or not.

Consumers choose between the two platforms located at the endpoints of the interval $x \in[0,1]$. The intrinsic quality of the platforms, $v$, is large enough so the market is completely covered. ${ }^{8}$ The platforms differ in the eyes of consumers only in price and in the number of third-party extensions available. A consumer denoted by $i$ receives utility $u_{i 1}=\left(v-t x_{i}\right)+b n_{e 1}-p_{1}$ if buying platform 1 and utility $u_{i 2}=\left(v-t\left(1-x_{i}\right)\right)+b n_{e 2}-p_{2}$ if buying platform 2. The number of third-parties available at platform 1 and 2 are given by $n_{e 1}$ and $n_{e 2}$. Platform prices are $p_{1}$ and $p_{2}$. The transportation cost parameter, $t$, measures the intensity of competition between the platforms.

Extension providers may develop extensions for both platforms. If both platforms are open, extension providers make the decision to develop for one platform independently from the decision to develop for the other. There is thus no direct competition for extension providers between the

\footnotetext{
${ }^{8}$ If not, the platforms are local monopolies and the results from the monopoly model hold. The condition needed when both platforms are closed is $v>\frac{3 t}{2}$. When both firm provide open platforms the condition is $v>\frac{6 f t-a^{2}-3 a b}{4 f}$. When one platform is closed and the other is open the conditions are $a b f(9 t-4 v)>a^{3} b+f\left(6 f t(3 t-2 v)+b^{2} v\right)+a^{2}\left(b^{2}+\right.$ $f(v-3 t))$ and $f\left(b^{2}(3 t-v)+6 f t(2 v-3 t)\right)>a\left(a^{2} b+2 a b^{2}+b^{3}-3 a f t-12 b f t+(a+4 b) f v\right)$.
} 
firms. Extension providers must pay the fixed development cost twice if they wish to supply an extension for both platforms. Conditional on the number of consumers at each platform, an extension provider $j$ has profits $\pi_{j k}=a n_{c k}-f y_{j}-s_{k}$ from each platform $k \in\{1,2\}$. The costs of developing extensions are high enough to ensure that some developers always stay out of the market. ${ }^{9}$

\subsection{Stage 2: Equilibrium Prices and Fees/Subsidies}

If both platforms are closed the model reduces to the standard Hotelling model. For the consumer indifferent between purchasing the platform from firm 1 or firm $2, v-t x_{i n}-p_{1}=v-(1-t) x_{i n}-p_{2}$ holds. Then demand for firm 1's platform is $n_{c 1}=\frac{1}{2}+\frac{p_{2}-p_{1}}{2 t}$ and demand for firm 2's platform is $n_{c 2}=1-n_{c 1}$. The firms simultaneously set price to consumers to maximize

$$
\pi_{k C C}=p_{k} n_{c k}
$$

This results in equilibrium prices of $p_{k}^{*}=t$, and profits of $\pi_{k C C}^{*}=\frac{t}{2}$. The second order conditions, $-\frac{1}{t}<0$, are satisfied. Consumer surplus is $C S_{C C}^{*}=$ $\int_{0}^{x_{i n}^{*}}\left(v-t x-p_{1}^{*}\right) d x+\int_{x_{i n}^{*}}^{1}\left(v-t(1-x)-p_{2}^{*}\right) d x=v-\frac{5 t}{4}$. As is standard, prices and profits are decreasing in the intensity of competition between the firms.

When both platforms are open the consumer indifferent between purchasing platform 1 and purchasing platform 2 is located the $x_{i}$ that satisfies $v+b n_{e 1}-t x_{i}-p_{1}=v+b n_{e 2}-(1-t) x_{i}-p_{2}$. Demand for firm 1's platform conditional on the number of extensions at each platform is $n_{c 1}^{\text {cond }}=$ $\frac{1}{2}+\frac{b n_{e 1}-b n_{e 2}}{2 t}+\frac{p_{2}-p_{1}}{2 t}$, and demand for firm 2's platform is $n_{c 2}^{c o n d}=1-n_{c 1}^{c o n d}$. The developer indifferent between developing an extension for platform $k$ and not developing one is located at $y_{k}=\frac{1}{f}\left(a n_{c k}-s_{k}\right)$. Demand for developing extensions for platform $k$ conditional on the number of consumer purchasing each platform is then $n_{e k}^{c o n d}=\frac{1}{f}\left(a n_{c k}-s_{k}\right)$. To obtain demands as functions of prices on both sides of the market we simultaneously solve the equations $n_{c 1}=n_{c 1}^{\text {cond }}, n_{c 2}=n_{c 2}^{\text {cond }}, n_{e 1}=n_{e 1}^{\text {cond }}$ and $n_{e 2}=n_{e 2}^{\text {cond }}$. This

\footnotetext{
${ }^{9}$ The assumptions needed are $f>\frac{a+b}{4}$ when the platforms are open and $f\left(a^{2}+4 a b+\right.$ $\left.\left.b^{2}+3(a+b-4 f) t\right)<a b(a+b)\right)$ when one platform is open and the other is closed.
} 
gives

$$
\begin{aligned}
& n_{c 1}=\frac{b\left(s_{2}-a-s_{1}\right)+f\left(p_{2}-p_{1}+t\right)}{2(f t-a b)}, \\
& n_{c 2}=\frac{b\left(s_{1}-a-s_{2}\right)+f\left(p_{1}-p_{2}+t\right)}{2(f t-a b)}, \\
& n_{e 1}=\frac{a\left(b\left(s_{1}+s_{2}\right)+f\left(p_{2}-p_{1}+t\right)\right)-a^{2} b-2 f s_{1} t}{2 f(f t-a b)}, \text { and } \\
& n_{e 2}=\frac{a\left(b\left(s_{1}+s_{2}\right)+f\left(p_{1}-p_{2}+t\right)\right)-a^{2} b-2 f s_{2} t}{2 f(f t-a b)} .
\end{aligned}
$$

The firms simultaneously set prices, $p_{k}$, to consumers and the fees(subsidies) to extension providers, $s_{k}$, to maximize

$$
\pi_{k O O}=p_{k} n_{c k}+s_{k} n_{e k}
$$

Equilibrium prices are $p_{k}^{*}=t-\frac{1}{4 f}(a(a+3 b))$ and $s_{k}^{*}=\frac{1}{4}(a-b)$. Profits, consumer surplus and total extension provider profits at these prices are

$$
\begin{aligned}
\pi_{k O O}^{*}= & \frac{t}{2}-\frac{a^{2}+6 a b+b^{2}}{16 f} \\
C S_{O O}^{*}= & \int_{0}^{x_{i n}^{*}}\left(v+b n_{e 1}^{*}-t x-p_{1}^{*}\right) d x+ \\
& \int_{x_{i n}^{*}}^{1}\left(v+b n_{e 2}^{*}-t(1-x)-p_{2}^{*}\right) d x \\
= & v-\frac{5 f t-a^{2}-4 a b-b^{2}}{4 f} \\
\Pi_{O O}^{*}= & \int_{0}^{y_{1}^{*}}\left(a n_{c 1}^{*}-f x-s_{1}^{*}\right) d x+ \\
& \int_{0}^{y_{2}^{*}}\left(a n_{c 2}^{*}-f x-s_{2}^{*}\right) d x \\
= & \frac{(a+b)^{2}}{16 f}
\end{aligned}
$$

The second order conditions, $-\frac{f}{f t-a b}<0,-\frac{2 f t-a b}{f(f t-a b)}<0$, and $\frac{8 f t-a^{2}-6 a b-b^{2}}{4(a b-f t)^{2}}>$ 0 are satisfied for $4 f t-(a+b)^{2}>0$. In equilibrium, firms balance price to consumers with fees (or subsidies) to extension providers so as to best internalize cross-group externalities. Prices and profits are lower than when the platforms are closed because both platforms have strong incentives to cut 
price to consumers. These incentives are increasing in the size of the crossgroup externalities. A price cut when open not only attracts more consumers but more extension providers as well. The cost of providing extensions $(f)$ affects the extent of this feedback effect. It is smaller the larger the costs of developing applications. Hence, profits (and prices) are increasing in the costs of providing extensions. Prices and profits are decreasing in the intensity of competition for consumers (decreases in $t$ ).

Consider now the case in which one platform is open and one closed. Assume firm 1 has the open platform and firm 2 has the closed platform. Conditional on the number of extensions available at platform 1, the consumer indifferent between the platforms is located at $x_{i n}$ with $x_{i n}$ satisfying $v+b n_{e 1}-t x_{i}-p_{1}=v-(1-t) x_{i}-p_{2}$. Demand for platform 1 conditional on the number of extension providers that develop for platform 1 is $n_{c 1}^{c o n d}=\frac{1}{2}+\frac{b n_{e 1}}{2 t}+\frac{p_{2}-p_{1}}{2 t}$ and demand for platform 2 is $n_{c 2}^{c o n d}=1-n_{c 1}^{\text {cond }}$. The developer indifferent between developing for platform 1 and not developing is located at $y_{1}=\frac{1}{f}\left(a n_{c 1}-s_{1}\right)$. Demand for developing extensions for platform 1 conditional on the number of consumers purchasing platform 1 is then $n_{e 1}^{\text {cond }}=\frac{1}{f}\left(a n_{c 1}-s_{1}\right)$. To obtain demands as functions of prices on both sides of the market, I simultaneously solve the equations $n_{c 1}=n_{c 1}^{\text {cond }}$, $n_{c 2}=n_{c 2}^{\text {cond }}$ and $n_{e 1}=n_{e 1}^{\text {cond }}$. This gives

$$
\begin{aligned}
& n_{c 1}=\frac{b s_{1}+f\left(p_{1}-p_{2}-t\right)}{a b-2 f t}, \\
& n_{c 2}=\frac{a b-b s_{1}-f\left(p_{1}-p_{2}+t\right)}{a b-2 f t}, \text { and } \\
& n_{e 1}=\frac{a\left(p_{1}-p_{2}-t\right)+2 s_{1} t}{a b-2 f t} .
\end{aligned}
$$

Firm 1 sets price to consumers and the fee (or subsidy) to extension providers to maximize

$$
\pi_{1 O C}=p_{1} n_{c 1}+s_{1} n_{e 1} .
$$

Firm 2 simultaneously sets price to consumers to maximize

$$
\pi_{2 O C}=p_{2} n_{c 2} .
$$


Equilibrium prices are

$$
\begin{aligned}
p_{1}^{*} & =\frac{(4 f t-a(a+b))(3 f t-a b)}{f\left(12 f t-a^{2}-4 a b-b^{2}\right)}, \\
s_{1}^{*} & =\frac{(a-b)(3 f t-a b)}{12 f t-a^{2}-4 a b-b^{2}}, \text { and } \\
p_{2}^{*} & =\frac{\left(6 f t-(a+b)^{2}\right)(2 f t-a b)}{f\left(12 f t-a^{2}-4 a b-b^{2}\right)} .
\end{aligned}
$$

Platform profits, consumer surplus and extension provider profits are

$$
\begin{aligned}
\pi_{1 O C}^{*}= & \frac{\left(8 f t-(a+b)^{2}\right)(a b-3 f t)^{2}}{f\left(a^{2}+4 a b+b^{2}-12 f t\right)^{2}}, \\
\pi_{2 O C}^{*}= & \frac{\left((a+b)^{2}-6 f t\right)^{2}(2 f t-a b)}{f\left(a^{2}+4 a b+b^{2}-12 f t\right)^{2}}, \\
C S_{O C}^{*}= & \int_{0}^{x_{i n}^{*}}\left(v+b n_{e 1 O C}^{*}-t x-p_{1 O C}^{*}\right) d x+ \\
& \int_{x_{i n}^{*}}^{1}\left(v-t(1-x)-p_{2 O C}^{*}\right) d x \\
= & \frac{2(a b-3 f t)\left(\left((a+b)^{2}-5 f t\right)(a b-3 f t)+f\left(a^{2}+4 a b+b^{2}-12 f t\right) v\right)}{f\left(a^{2}+4 a b+b^{2}-12 f t\right)^{2}}+ \\
& \frac{\left((a+b)^{2}-6 f t\right)\left(\left((a+b)^{2}-6 f t\right)(2 a b-5 f t)+2 f\left(a^{2}+4 a b+b^{2}-12 f t\right)(27)\right.}{2 f\left(a^{2}+4 a b+b^{2}-12 f t\right)^{2}} \\
\Pi_{O C}^{*} & \int_{0}^{y_{i O C}^{*}}\left(a n_{c 1 O C}^{*}-f y-s_{1 O C}^{*}\right) d y+\int_{0}^{y_{i O C}^{*}}\left(a n_{c 1 O C}^{*}-f y-s_{1 O C}^{*}\right) d y \\
= & \frac{(a+b)^{2}(a b-3 f t)^{2}}{2 f\left(a^{2}+4 a b+b^{2}-12 f t\right)^{2}} .
\end{aligned}
$$

The second order conditions $-\frac{2 f}{2 f t-a b}<0,-\frac{4 t}{2 f t-a b}<0$ and $\frac{8 f t-(a+b)^{2}}{(a b-2 f t)^{2}}>0$ are satisfied for $4 f t-(a+b)^{2}>0$. By reversing the identities of the platforms, we can get profits under the outcome Closed-Open. These profits are $\pi_{1 C O}^{*}=\pi_{2 O C}^{*}$ and $\pi_{2 C O}^{*}=\pi_{1 O C}^{*}$. Application developers are subsidized if $b>a$. The size of cross-group externalities and the costs of developing applications can either increase or decrease profits. The reason is that while cross-group externalities benefit the platform, they also lead to intensified competition for consumers (more on this below). 
Firm 2

\begin{tabular}{cc|c|c|} 
& & $\mathrm{C}$ & $\mathrm{O}$ \\
\hline Firm 1 & $\mathrm{C}$ & $\left(\pi_{1 C C}^{*}, \pi_{2 C C}^{*}\right)$ & $\left(\pi_{1 C O}^{*}, \pi_{2 C O}^{*}\right)$ \\
& $\mathrm{O}$ & $\left(\pi_{1 O C}^{*}, \pi_{2 O C}^{*}\right)$ & $\left(\pi_{1 O O}^{*}, \pi_{2 O O}^{*}\right)$
\end{tabular}

Figure 3: The simultaneous game played by private firms before they set prices and fees.

\subsection{Stage 1: Private versus Social Incentives}

Let us now compare private and social incentives to provide an open platform. Start with social incentives. Which of the four possible combinations of open and closed platforms would maximize social welfare? Suppose we measure social welfare as the unweighted sum of consumer surplus, firm profits and third-party producer profits. Then, it is best for society as a whole to have both platforms open if

$$
\begin{aligned}
& C S_{O O}^{*}+\pi_{1 O O}^{*}+\pi_{2 O O}^{*}+\Pi_{1 O O}^{*}>C S_{C C}^{*}+\pi_{1 C C}^{*}+\pi_{2 C C}^{*}, \\
& C S_{O O}^{*}+\pi_{1 O O}^{*}+\pi_{2 O O}^{*}+\Pi_{1 O O}^{*}>C S_{O C}^{*}+\pi_{1 O C}^{*}+\pi_{2 O C}^{*}+\Pi_{O C}^{*}, \\
& C S_{O O}^{*}+\pi_{1 O O}^{*}+\pi_{2 O O}^{*}+\Pi_{1 O O}^{*}>C S_{C O}^{*}+\pi_{1 C O}^{*}+\pi_{2 C O}^{*}+\Pi_{C O}^{*}
\end{aligned}
$$

The first condition always holds since the difference between the left and right side is $\frac{1}{f}\left((a+b)^{2}\right)>0$. The second and third conditions are equivalent in this model. It is possible to show that they hold for $f t$ sufficiently large. ${ }^{10}$ Hence, for sufficiently large $f t$ it is socially optimal to have both platforms open.

If the firms privately choose between open and closed platforms, they play the simultaneous move game in figure 3 . Each firm will have a dominant strategy to provide an open platform if

$$
\begin{aligned}
& \pi_{1 O C}^{*}>\pi_{1 C C}^{*}, \\
& \pi_{2 C O}^{*}>\pi_{2 C C}^{*}, \\
& \pi_{1 O O}^{*}>\pi_{1 C O}^{*}, \text { and } \\
& \pi_{2 O O}^{*}>\pi_{2 O C}^{*} .
\end{aligned}
$$

\footnotetext{
${ }^{10}$ The difference between the left and right side can be simplified to $4\left(17 a^{4}+72 a^{3} b+\right.$ $\left.106 a^{2} b^{2}+72 a b^{3}+17 b^{4}\right) f t<3(a+b)^{2}\left(a^{4}+8 a^{3} b+10 a^{2} b^{2}+8 a b^{3}+b^{4}+72 f^{2} t^{2}\right)$, which holds for sufficiently large $f t$.
} 
The first two and the second two conditions are equivalent. The first two conditions hold for $2 a^{2} b^{2}+\left(a^{2}-6 a b+b^{2}\right) f t>0$, which is positive for large $f t$ only if $a^{2}-6 a b+b^{2}>0$ or equivalently if $(a-b)^{2}-4 a b>0$. Hence, for large $f t$ and sufficiently small difference in cross group externalities, so that $(a-b)^{2}-4 a b<0$, firms will not have incentives to provide open platforms even if it would be socially desirable. The reason is that opening the platform makes the rival more aggressive in pricing.

Proposition 2. There exist cases in which competing platforms exclude third-party providers in a sub-game perfect equilibrium. This exclusion is socially inefficient both because third-party providers are excluded and because it relaxes competition for consumers.

To see that competition is intensified, consider the best response functions of the firms. The best response functions for price for firm 1 when its platform is closed are $p_{1}\left(p_{2}\right)_{C C}=\frac{t+p_{2}}{2}$, and $p_{1}\left(p_{2}, s_{2}\right)_{C O}=\frac{t+p_{2}}{2}-\frac{b\left(a-s_{2}\right)}{2 f}$. When firm 1 provides an open platform the best response functions are $p_{1}\left(s_{1}, p_{2}\right)_{O C}=\frac{t+p_{2}}{2}-\frac{(a+b) s_{1}}{2 f}$, and $p_{1}\left(s_{1}, p_{2}, s_{2}\right)_{O O}=\frac{t+p_{2}}{2}-\frac{(a+b) s_{1}}{2 f}-\frac{b\left(a-s_{2}\right)}{2 f}$. Studying these, we can see that because $\frac{b\left(a-s_{2}\right)}{2 f}>0$ in equilibrium, firm 1 has incentives to price more aggressively if firm 2 provides an open platform.

\section{Conclusions}

Do private firms allow third-parties to access their platform and develop extensions for their product when it is socially desirable to do so? In this paper I proposed two reasons for why this may not be true. First, a private firm may not be able to internalize all benefits from cross-group externalities arising with third-party extensions. Second, firms may have strategic incentives to shut out producers of third-party extensions as a device to relax competition for consumers.

My analysis suggests that private incentives to allow third-parties access to platforms may be insufficient. It hence supports the argument that policy should be directed towards supporting open platforms that allow third-parties to access the platform and develop extensions for it. 


\section{References}

Armstrong, M. (2006). Competition in two-sided markets. RAND Journal of Economics 37, 668-691.

Bork, R. (1978). The antitrust paradox. Basic Books.

Bowman, W. (1957). Tying arrangements and the leverage problem. The Yale Law Journal 67, 19-36.

Caillaud, B. and B. Jullien (2003). Chicken and egg: Competition among intermediation service providers. RAND Journal of Economics 34, 309328.

Carlton, D. and M. Waldman (2002). The strategic use of tying to preserve and create market power in evolving industries. RAND Journal of Economics 33, 194-220.

Choi, J. P. (2006). Tying in two-sided markets with multi-homing. NET Institute Working Paper 06-04.

Choi, J. P. and C. Stefanadis (2001). Tying, investment and the dynamic leverage theory. RAND Journal of Economics 32, 52-71.

Church, J. and N. Gandal (2000). Systems competition, vertical merger, and foreclosure. Journal of Economics and Management Strategy 9, 25-51.

Economides, N. (1989). Desireability of compatibility in the absence of network externalities. American Economic Review 79, 1165-1181.

Economides, N. (1998). The incentive for non-price discrimination by an input monopolist. International Journal of Industrial Organization 16, 271-284.

Farrell, J. and M. Katz (2000). Innovation, rent extraction and integration in systems markets. Journal of Industrial Economics 48, 413-432.

Farrell, J., H. Monroe, and G. Saloner (1998). The vertical organization of industry: Systems competition versus component competition. Journal of Economics and Management Strategy 7, 143-182.

Hagiu, A. (2006). Pricing and commitment by two-sided platform. RAND Journal of Economics 37, 720-737. 
Matutes, C. and P. Regibeau (1988). Mix and match: Product compatibility without network externalities. RAND Journal of Economics 19, 221-234.

Nalebuff, B. (2004, Feb). Bundling as an entry barrier. Quarterly Journal of Economics 119, 159-187.

Rochet, J.-C. and J. Tirole (2003). Platform competition in two-sided markets. Journal of the European Economic Association 1, 990-1029.

Rochet, J.-C. and J. Tirole (2006). Two-sided markets: A progress report. RAND Journal of Economics 35, 645-667.

Whinston, M. D. (1990). Tying, foreclosure, and exclusion. American Economic Review 80, 837-859. 